\title{
Accelerating Energy Renovation Solution for Zero Energy Buildings and Neighbourhoods-The Experience of the RenoZEB Project ${ }^{+}$
}

\author{
Michele Vavallo 1,*, Marco Arnesano 2, Gian Marco Revel 2, Asier Mediavilla ${ }^{3}$, \\ Ane Ferreiro Sistiaga ${ }^{4}$, Alessandro Pracucci ${ }^{5}$, Sara Magnani ${ }^{5}$ and Oscar Casadei ${ }^{5}$ \\ 1 R\&D Department, Solintel M\&P S. L. Avda. de la Industria n. 4, edificio 1, \\ Oficina 1B, 28108 Alcobendas, Madrid, Spain \\ 2 Department of Industrial Engineering and Mathematical Sciences, Università Politecnica delle Marche Via \\ Brecce Bianche 12, 60131 Ancona, Italy \\ 3 Tecnalia Research \& Innovation, Parque Tecnológico de Bizkaia, Astondo Bidea, \\ Edificio 700, 48160 Derio, Spain \\ 4 R\&D Department, CYPE Soft SL, Avenida Eusebio Sempere, 5, 03003 Alicante, Spain \\ 5 Focchi S.p.A., Via Cornacchiara, 47824 Poggio Torriana Rimini, Italy \\ * Correspondence: michele.vavallo@solintel.eu \\ † Presented at the Sustainable Places 2019 (SP 2019), Cagliari, Italy, 5-7 June 2019.
}

Received: 18 July 2019

\begin{abstract}
Buildings are the key factor to transform cities and to contribute to recent European energy efficiency objectives for 2030 and long-term 2050. New buildings account to only 1-2\% annually. Yet, ninety percent of the existing building stock in Europe was built before 1990, it is therefore necessary to promote their energy renovation to achieve the set objectives. Renovation solutions are available on the market, yet a wrong implementation and integration due to a lack of knowledge neither maximizes the energy performance of the post-retrofitting nor the financial optimisation and viability of the projects. This paper presents research on a plug \& play, modular, easy installable façade and ICT decision making technologies to provide affordable solutions in order to overcome those deep renovation barriers. The paper sets out by defining a value framework that can be applied by real estate investors for making better retrofitting decisions for residential buildings, through mapping targeted building typologies and investigating new building revalorisation strategies, new renovation concepts and KPIs for evaluation. Thereafter the paper presents the modular and easy-to-install façade system that is replicable and scalable at European level.
\end{abstract}

Keywords: energy-efficient buildings; deep renovation; plug\&play façade; retrofitting; BIM; decision making tools

\section{Introduction}

According to the EPBD Recast Directive, currently only 1-2\% of the building stock is replaced annually. As a result, the successful accomplishment of the emission reduction target by 2050, involves specially the need to retrofit almost all the European building stock at a rate of $2.9 \%$ of buildings per year, versus current $1.2 \%$. Buildings remain as the key factor to transform cities in energy efficient environments and contributing to the new European objectives (40-27-27-15) by 2030 [1]. However, currently retrofitting processes are expensive, with many uncertainties regarding the built result, complex for the industry and disturbing for the occupant [2]. Consequently, the energy renovation rate and even the performance of these renovation projects are rather low. The benefits and costs ratios of the renovation solutions evaluated in real projects are diminished by the poor real performance of the selected technologies, potentially caused by a wrong implementation and 
integration process and the lack of smart monitoring and control systems able to introduce the human behaviour variable. This paper suggests tackling this issue through proper implementation and integration of them to maximize the energy performance of the post-retrofitting building and their impact on the value of the renovated property. Moreover, the vast majority of renovation processes are not financially optimised and viable because the data flow during the renovation cycle fails, producing inefficiencies and additional costs, thus increasing the risk of property owners and investors. Hence, there are several inefficacies affecting the performance of the renovation strategy like the information that is often not properly shared, generates multiple errors and duplicates efforts which could be tackled. The information could flow properly among stakeholders, exploiting attractive technological solutions, a well-designed renovation methodology based on a cloud collaborative environment aiming at the involvement of all key stakeholders along the "life cycle process of the renovation".

The objective of the research presented in this paper is to overcome the barriers of deep renovation and to promote innovative solutions with a high replicability potential at European scale contributing to create a large-scale nZEB renovation Market in Europe transforming the residential building stock to match the net-zero energy standards at affordable price. This paper refers to the EU collaborative research project titled RenoZEB, which is focused on unlocking the nZEB renovation market, leveraging the gain on property value through a new systemic approach to retrofitting that will include innovative components, processes and decision-making methodologies and tools to guide all value-chain actors in the nZEB building renovation process.

\section{Research Methodology}

This paper presents the currently on-going technical research within RenoZEB, which is 18 months out of its 42 months duration [3]. The project set out by defining a value framework that can be applied in making retrofitting decisions for residential buildings by real estate investors, mapping the targeted building typologies and investigating new building revalorisation strategies, new renovation concepts and KPIs for evaluation. The project aims to provide a holistic vision for the renovation market, tackling one by one the issues, from monitoring, to design up to construction, mainly focusing on two aspects: offering a series of IT tools that will help real estate developers and construction companies to be confident about their investments when renovating; providing architects with a modular and easy-to-install façade system that can be scalable at European level.

The first core aspect in RenoZEB is the use of Open BIM to support the renovation methodology, which fosters the digitalization of the renovation value chain, in line with leading technological trends. In RenoZEB a cloud collaboration platform and a set of decision-making tools, which will support the different actors in the renovation process, is being developed. These systems work around an open and standardized format, the IFC model, linked to different information (costs, energy performance, code compliance, etc.). This technology allows users to share, navigate or comment the models, create and assign tasks and issues to other users, manage, evaluate and compare different scenarios thanks to a KPI system and the support to a web visualization of BIM models.

The second core aspect of the project is to develop a set of plug \& play modules suitable for buildings' envelope renovation. The RenoZEB envelope system aims at providing a façade solution that could be tailored case by case in line with building of reference, KPIs typical of the market, geocluster. In this framework, the concept design provides a solution adaptable to the different possibilities of application offering a standardised system able to include a range of components selected on the base of the specific building to be refurbished.

To demonstrate project viability, empirical output of the RenoZEB project solutions will be demonstrated inside two real pilot and three virtual pilot buildings. These pilots represent the main typologies within the existing building stock in Europe subjected for deep renovation, namely: public and private apartment complexes and commercial assets. 


\section{Actual Research findings}

\section{1. $n$ D Collaborative Platform}

The RenoZEB nD Collaboration Platform is an online portal for the project. It follows the principles of a Common Data Environment (CDE) [4], as a single information model for the project, which enables better decisions thanks to a more complete, reliable and up-to-date information, agreed by all actors and, as a consequence, a better performing final product (the building) and a more efficient process in terms of time, cost and error savings. Full and smooth digital workflows during the whole project life-cycle are still uncommon in current practices and in renovation is even more evident. The platform is developed around widespread standard technologies, such as IFC or $\mathrm{BCF}$ for the management of the BIM information, RESTful web services for interacting with the server from any external interface, and WebGL standards for the web visualization. The use of REST based web services permits the integration of any third-party application into the platform and a huge potential of future extensibility. Initially two external type of tools are being integrated in the project: CYPE tools for generating energy simulation based KPIs and a Knowledge Based Engine (by the University of Salford) to support the decision making in early-stages.

Figure 1 shows some examples of already implemented features, such as a KPI management system, which allows comparing KPIs in different renovation scenarios, according to user priorities, and a web viewer module for IFC, both in detailed mode and georeferenced in a GIS context.
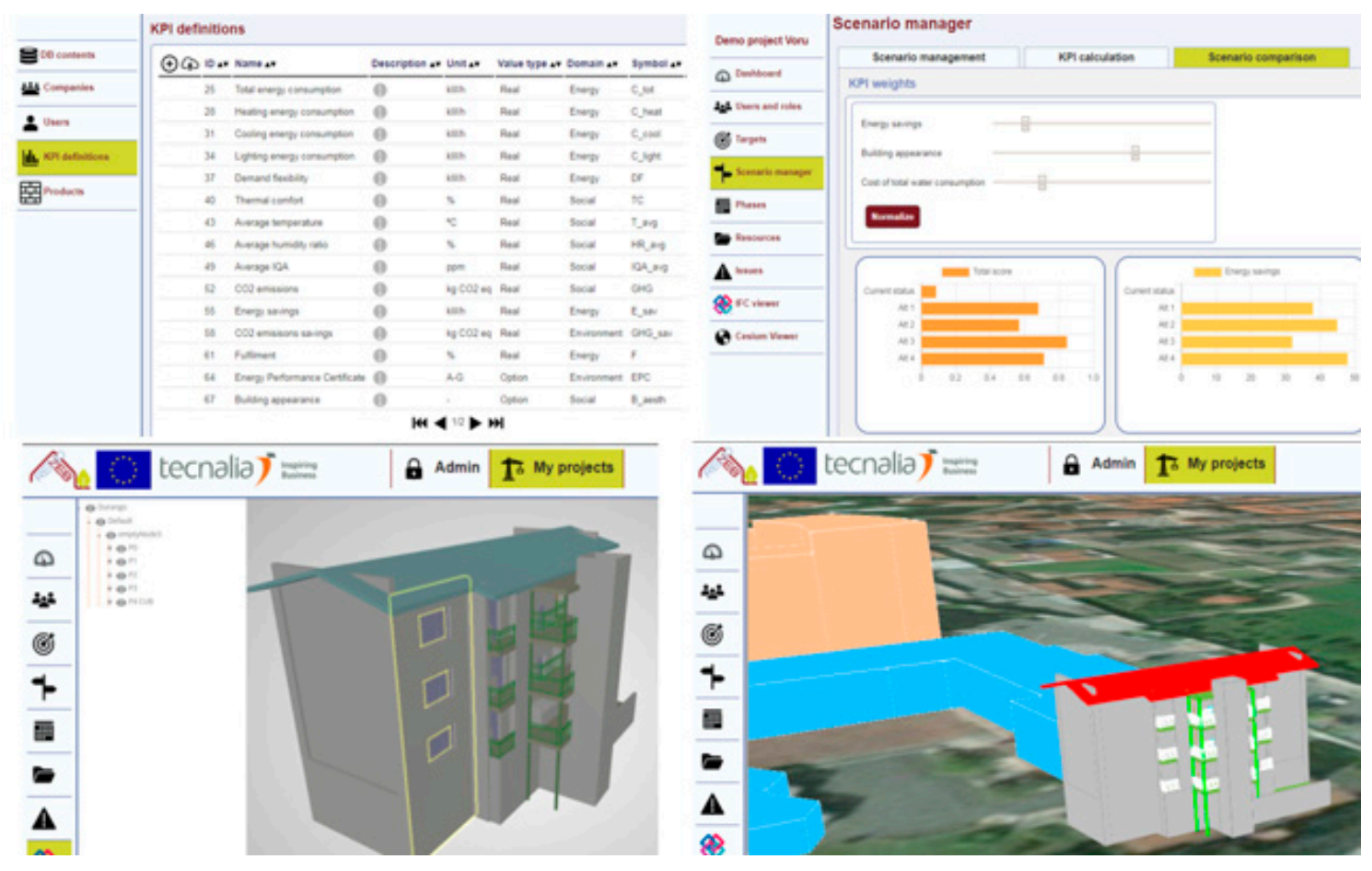

Figure 1. nD Collaborative platform: KPI management \& evaluation (top) and IFC viewers (bottom).

\subsection{Decision Making Tools}

RenoZEB works with an Open BIM workflow that knits together the software tools within the platform. The main property and advantage of the Open BIM workflow is that it is based on the use of IFC standard exchange files. By working with standard formats, there is improved communication amongst users, since these formats can be read by most tools used for project development. Therefore, the main element of the project lies in the data it is composed of, and not in the programs used to develop it. The objective of this set of BIM tools is to help stakeholders in the decision-making process of renovation. RenoZEB will use BIM to allow to incorporate, in the renovation process, a new methodology that will help to save time and money due to the possibility of having all the information compiled under the same roof and because it allows to compare different renovation 
solutions and choose the one with the best performance. The RenoZEB methodology follows the next steps: data capture throughout different methods: laser scanning, photogrammetry, etc.; BIM modelling with the data obtained in the previous step; development of Building Energy Model (BEM) to perform energy simulation (the definition of the BEM model is assisted with a RenoZEB ecatalogue of construction products for renovation and with the software Open BIM RenoZEB-Focchi Façades. Figure 2); comparison of the different solutions to apply which is the best for the specific project. This decision will be made based on the Key Performance Indicator that had been defined in the project as total energy demand and consumption.

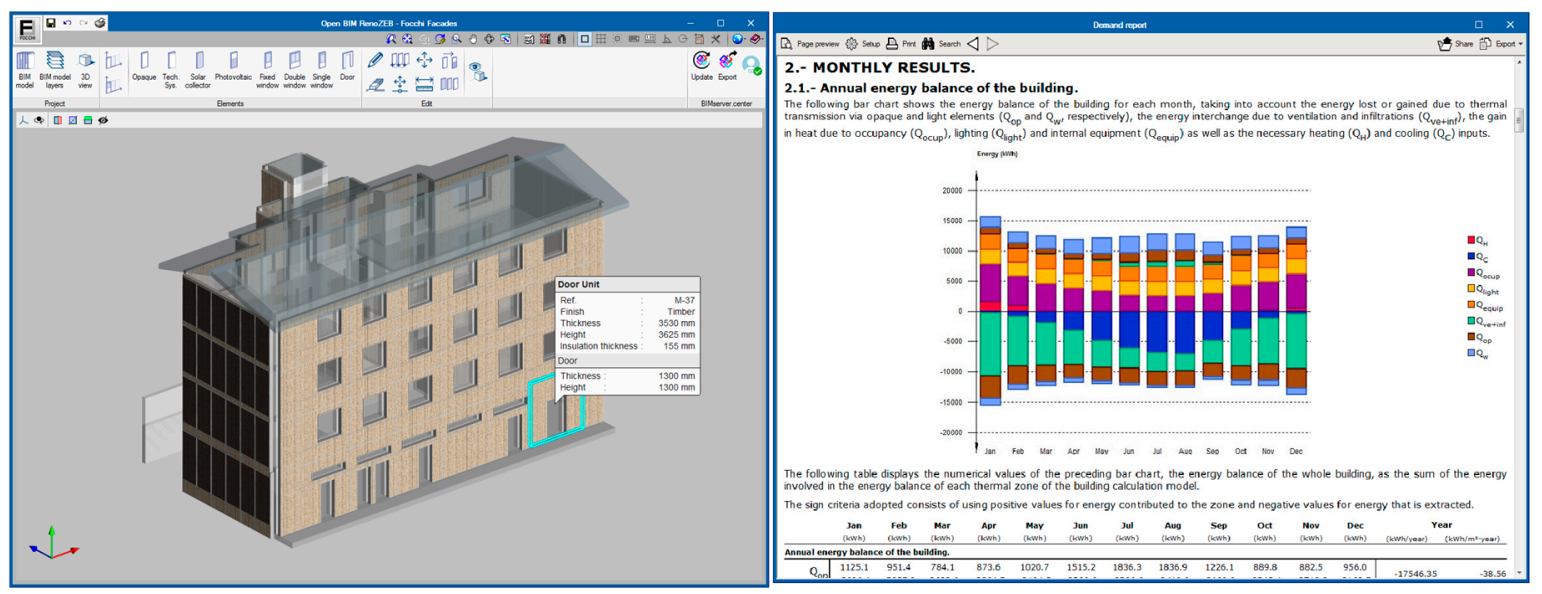

Figure 2. Renovation configurator tool (left) and summary of simulation results (right).

\subsection{Plug and Play Façade System}

The design approach has been based on a Multi Criteria Decision Matrix (MCDM) to define the most important components and configurations that are suitable for the renovation market. The outcome of the design process turned out to provide a library of façade modules ranging from the opaque unit with different external finishing to a panel with embedded sensors and technical components in the window unit. The modules all have the common characteristic of being plug \& play because of the prefabrication process that has been developed to maximize off-site activities and consequently reducing number and duration of the on-site operations.

The final list of the façade modules includes the possibility to integrate the following components:

- Prefabricated window module and roller shutter;

- Multifunctional insulation board;

- Ventilation devices;

- Building Integrated Photovoltaics (BIPV);

- $\quad$ Building Integrated Solar Thermal;

- Façade controller;

- Façade-integrated sensors;

The Figure 3 shows the façade modules suite, with the required components for application on existing façades. Among the different configurations, the façade-integrated sensors allow measuring the outdoor conditions, which have an impact on the energy performance of buildings and on indoor comfort. The main scope is to validate the use of sensors embedded into the façade to improve the building monitoring and control. Several quantities can be measured at the façade, such as, air temperature, relative humidity, air quality, solar radiation and illuminance. In the case of RenoZEB, the idea is to measure a subset of these quantities, those useful for the implementation of the façade control. To this end, a prototype was developed with the integration of two sensors:

1. Solar radiation: measurement of the amount of solar radiation $\left(\mathrm{W} / \mathrm{m}^{2}\right)$ incident on the building façade (exterior).

2. Light: measurement of the outdoor daylight on the façade plane (lux). 


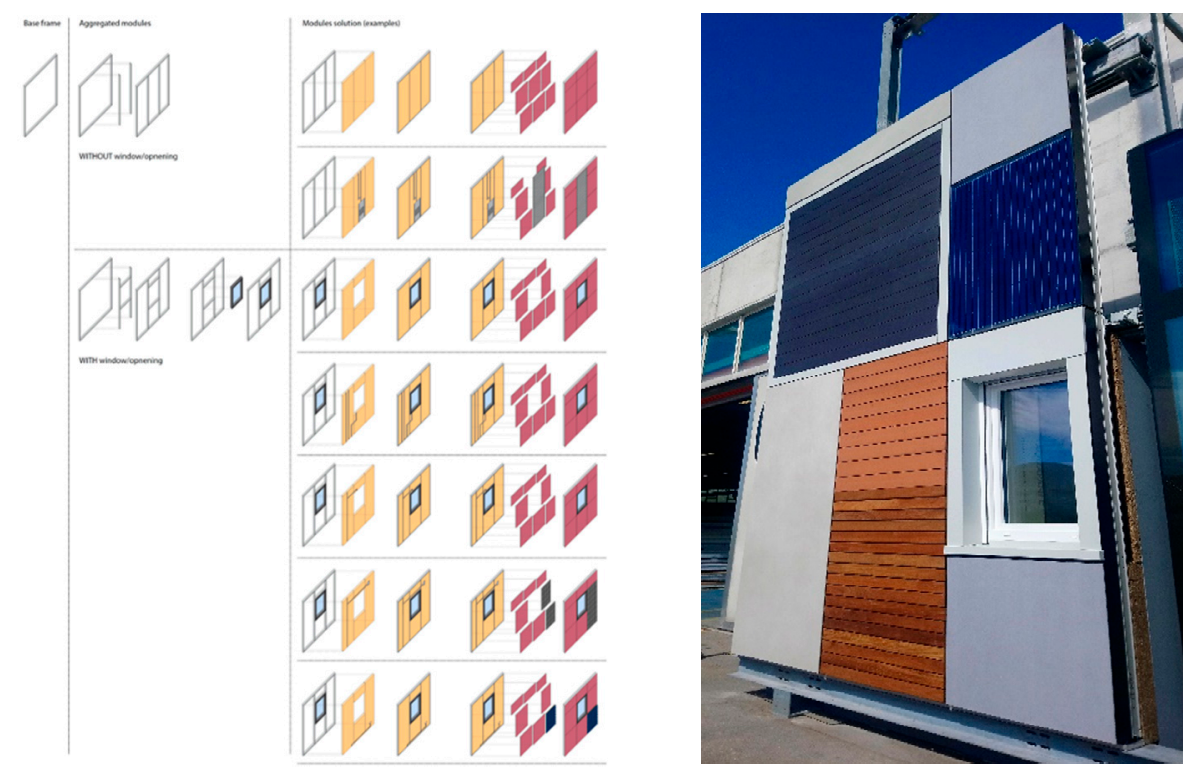

Figure 3. Mock-up of the RenoZEB facade modules and components library.

Sensors are embedded in the façade together with the required microcontroller to acquire and transmit data, wirelessly. In this way, the IoT approach has been applied to obtain a façade element capable of communicating relevant data and make them available for control services. Based on that, the idea of the control is to develop a function that relates the measured information at the façade with the operation of the façade. The function is developed by state-of-the-art simulations with the FENER webtool https://fener-webport.ise.fraunhofer.de/, which allows sophisticated façade control algorithms to be simulated. By applying one of these control algorithms and calculating both the measured variables at the façade and the resulting operation of the façade, a correlation between the two for a particular case study is obtained. The first prototype of the IoT data acquisition system to be embedded into the façade module has been developed and tested to demonstrate the sensing capabilities in relation to the control requirements. Moreover, the manufacturing process has been defined so that the façade modules is ready for the plug \& play installation. Finally, to evaluate the impact of the proposed retrofit solution as compared to existing baseline scenario, dynamic simulations have been run with the Fener tool considering an office and a residential building. In the baseline scenario, the roller blinds are activated according control algorithms described above. For the office case, by taking into account only the occupied hours, the results indicate that the application of the exterior roller blind would provide an important reduction of cooling energy demand $(63 \%)$. For the residential case, the results indicate that the application of the exterior roller blind would result in a reduction of both heating energy demand (13\%) and lighting energy demand (58\%).

\section{Conclusions}

This paper presented the research activities performed by the RenoZEB project to overcome the barriers of deep renovation, promoting innovation, from one hand, introducing the use of the Open BIM and IFC model to support the renovation methodology and including the digitalization of the renovation value chain. From the other hand, developing the plug \& play modules, suitable for façade buildings' envelope renovation. Future investigations will address several other activities like the definition of a knowledge-based tool for supporting the decision-making process of RenoZEBrenovation in Real Estate industry and a guideline for supporting the decision-making stages of the whole renovation process for residential buildings.

In relation to the $\mathrm{nD}$ platform, the next steps include the support of additional collaboration features around the BIM model (add annotations, comments, send requests, attach files...) and to integrate external tools into the workflow. To do so, specific use cases will be defined for each demo 
project and validated with the main actors of each project, gathering valuable feedback to improve the usefulness of the platform.

The plug \& play modules will be manufactured, tested and afterward installed inside two real Buildings (Demonstrators in Spain and Estonia) to demonstrate the RenoZEB façade with its Energy Efficiency performances, to contribute in the validation of the industrialization of the system and the adaptability to owners and users request, to direct the mass customization of the solution for future market development and promotion.

Author Contributions: Conceptualization, M.V. and M.A.; methodology, M.V., M.A., G.M.R., A.M., A.F.S., A.P., S.M. and O.C.; investigation, M.V., M.A., A.M., A.F.S. and A.P.; resources, M.V., M.A., A.M., A.F.S. and A.P.; writing-original draft preparation, M.V., M.A., A.M., A.F.S. and A.P.; writing-review and editing, M.V., M.A., A.M., A.F.S. and A.P.; funding acquisition, M.V.

Funding: This research has received funding from the European Union's Horizon 2020 research and innovation program under Grant Agreement No. 768718.

Acknowledgments: The authors want to thank the RenoZEB partners for the fruitful discussions and collaboration.

Conflicts of Interest: The authors declare no conflict of interest.

\section{References}

1. Climate Action. Available online: http://ec.europa.eu/clima/policies/2030/index_en.htm (accessed on 1 May 2019).

2. Directive 2010/31/EU EPBD Recast 2010. Available online: https://eurlex.europa.eu/LexUriServ/LexUriServ.do?uri=OJ:L:2010:153:0013:0035:EN:PDF (accessed on 1 May 2019).

3. Accelerating Energy renovation solution for Zero Energy buildings and Neighbourhoods. Available online: https://renozeb.eu/ (accessed on 1 May 2019).

4. Preidel, C.; Borrmann, A.; Oberender, C.; Tretheway, M. Seamless Integration of Common Data Environment Access into BIM Authoring Applications: the BIM Integration Framework. In Proceedings of the 11th European Conference on Product and Process Modelling, Limassol, Cyprus; 7-9 September 2016. pp. 119-128.

(C) 2019 by the authors. Licensee MDPI, Basel, Switzerland. This article is an open access article distributed under the terms and conditions of the Creative Commons Attribution (CC BY) license (http://creativecommons.org/licenses/by/4.0/). 